\title{
Towards Participatory MOOCs
}

Amit Pariyar, Postdoctoral Researcher, Institute of Social Informatics and Technological Innovations, University Malaysia Sarawak, amitpariyar@gmail.com

Amit Pariyar is the designer of the community-led MOOCs for UNIMAS Competen-SEA project.

Professor Dr. Narayanan Kulathuramaiyer, Director, Institute of Social Informatics and Technological Innovations, University Malaysia Sarawak, nara@unimas.my

Narayanan Kulathuramaiyer is the team leader and the designer of the community-led MOOCs for the UNIMAS Competen-SEA project.

Dr. Poline Bala, Associate Professor, Faculty of Social Science, University Malaysia Sarawak, bpoline@unimas.my

Poline Bala is the knowledge engineer and domain specialist for UNIMAS Competen-SEA project.

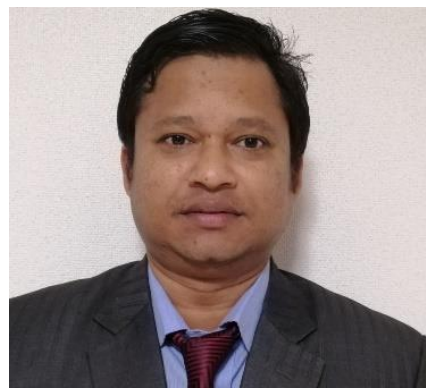

Dr. Amit Pariyar is a Postdoctoral Researcher at the Institute of Social Informatics and Technological Innovations (ISITI) in Universiti Malaysia Sarawak (UNIMAS). He received his PhD in Informatics from Kyoto University, Japan. His research papers are published in IEEE and Springer in the proceedings of international conferences and journals related to culture computing, social informatics, information and knowledge management. His research interests are in the areas of Knowledge Management, Social Informatics and ICT4D. He is a recipient of Nepal Bidhya Bhusan Class ' $A$ ' medal, a state honor for academic excellence in Nepal. He is the designer of the community-led MOOCs for the UNIMAS Competen-SEA project.

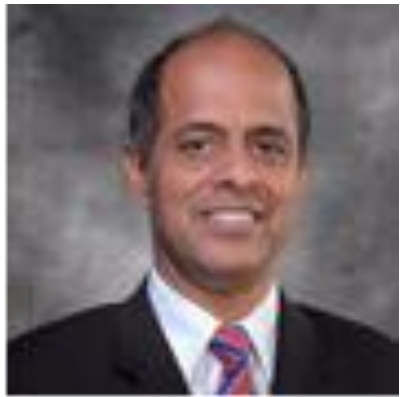

Professor Dr. Narayanan Kulathuramaiyer has served almost three decades in academia as one of the pioneer staff of Faculty of Computer Science and IT in Universiti Malaysia Sarawak (UNIMAS). He is currently the Director of the Institute of Social Informatics and Technological Innovations (ISITI) at UNIMAS. He received his Ph.D. in Computer Science from Graz University of Technology, Austria. He has published around 120 peer-reviewed papers on technology-based learning, data analytics and on making eLearning work in an information proliferation era. He has pioneered efforts in eLearning from heading the Virtual Campus Programme, Centre of Applied Learning and Multimedia, and initiating UNIMAS' first ever MOOC initiative on IT literacy. He is the team leader and the designer of the community-led MOOCs for the UNIMAS Competen-SEA project 


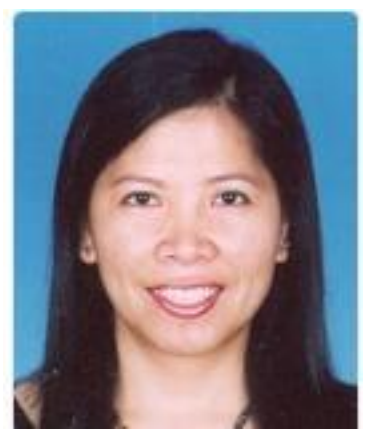

Dr. Poline Bala is an Associate Professor in the Faculty of Social Sciences, and a research fellow at the Institute of Social Informatics and Technological Innovations, University Malaysia Sarawak (UNIMAS). She obtained her Ph.D. in 2008 from Cambridge University. Her area of interest and research includes the impacts of political boundaries on the formation of cultural, political, and economic units in the border regions of Borneo. Most recently her research explores the role of technologies in the social transformation of Sarawak, particularly the introduction of Information Communication Technology (ICT) in rural areas. She is the knowledge engineer and domain specialist of the community led MOOCs for the UNIMAS Competen-SEA project

\begin{abstract}
This chapter presents a unique perspective on the participatory role of marginalized community in the knowledge exchange with our "Community Led MOOCs" by showcasing their ability to foster knowledge creation from the ground, and contribute in bridging the global local knowledge divide. The novel case of participatory MOOCs with single mother communities in Bario, a remote and rural region in the Borneo Island of Malaysia, redefines 'inclusive' and 'participatory' nature of learning by integrating community participation, their learning context and way of life. The outcome is a MOOC module on "Threading Beads" which represents the cultural knowledge preservation effort by the rural single mothers for future generations.
\end{abstract}

\title{
Introduction
}

The recent development in MOOCs (Massive Open Online Course) and mobile learning has shaped a landscape of potential educational breakthroughs for rural communities. Koller (2012) and Agarwal (2014), the leaders of mainstream MOOCs, see huge potential in benefiting the learner communities in the global south with specialized knowledge passed from the world class universities in the global north. On the other hand, (Sharples et.al, 2015) foresees MOOCs embracing various forms of affordances with mobile technologies to offer new methods of learning better suited to rural learners, for instance context-sensitive, geo-located and crowd learning. The optimism for inclusive learning with MOOCs is further raised with the growth in mobile penetration and internet connectivity. ITU has reported a general upward trend in developing countries in its percentage of population using the internet, which has increased from 7.7 per cent in 2005 to 45.3 per cent at the end of 2018 (ITU, 2018). These promising figures together with the MOOCs' philosophy of democratizing education through technology echoed in (Rhoads et al., 2013; Wulf et al., 2014; Rambe \& Moeti, 2016) has sparked interest among development practitioners into considering MOOCs as a viable alternative to meet the learning needs of developing countries.

However, as MOOCs' educational paradigm is maturing with technology, the recent development shows trends in departing from the original philosophy. From a commercial point of view, MOOCs is partly deviating from its notion of openness to revenue generation business model through certification and specialized programs. For southern learners, the added financial burden can create suboptimal learning experience (Kalman, 2014). The founder of class central Shah (2017) also backs up the need for true innovation in pricing to reach the 